\title{
Trichomes Size and Structure in Sunflower (Helianthus annuus L.) Leaf under Nitrogen Deficiency
}

\author{
Santosh Kumari* \\ Division of Plant Physiology, Indian Agricultural Research Institute, New Delhi, India \\ *Corresponding author
}

\section{A B S T R A C T}

\section{Keywords}

Nitrogen, Structure,

Size, Trichome,

Leaf, Sunflower

Article Info

Accepted:

15 February 2020

Available Online:

10 March 2020
Two types of glandular trichomes i.e. Capitate triangular glandular and Capitate globular glandular were recorded in sunflower. Nitrogen availability regulates globular glandular trichomes development from epidermal cells by cell division via cross talk of cytokinin in roots to plant metabolic pathways in leaves. The size of trichomes on sunflower leaves may be altered with the amino acid composition and levels mobilized from older leaves under nitrogen deficiency. Therefore, Trichome development is controlled by external fertilizer availability and internal plant processes involving carbon and nitrogen metabolism and phytohormones associated with these biosynthetic pathways.

\section{Introduction}

Trichomes may be simple hair covering leaf surface, reflect light, protect from UV radiation, and prevent water loss, therefore, affect photosynthesis by turgidity of leaves. Glandular or secretory trichomes may store chemicals which on volatilization attract insect or deter pest and herbivores. Glandular trichomes extend from the epidermal cells from a series of anticlinal and periclinal cell divisions. Most of the information related to the trichomes has arisen from cytochemical and ultrastructural studies. Plastids and endoplasmic reticulum has been associated with terpene secreting glands. The composition and concentration of terpene, sesquiterpene, flavonoids and phenylpropanoid have been shown to vary in different types of trichomes and with environmental conditions. Eugenol, isoeugenol and chavicol are the phenylpropene produced by the plants as pollinator attracting chemicals. The phenylpropene - forming enzymes are Nicotinamide adenine dinucleotide phosphate (NADPH) dependent reductases in basil.

Nitrogen affects synthesis of amino acids, protein, RNA and DNA. Therefore, cell division, elongation, cell wall materials, leaf growth, photosynthesis, primary and 
secondary metabolism, plant growth and biomass are altered with the availability of nitrogen fertilizer. Knowledge of trichome developmental biology and secretion of particular flavonoids, terpenoids, acyl sugars and methyl ketones will help in exploiting their potential in biotic and abiotic stress environments. The study was carried out to analyse the effect of nitrogen on trichome size and structure under nitrogen deficiency.

\section{Materials and Methods}

Sunflower genotype Morden was grown in pots size $(30 \mathrm{~cm} \times 30 \mathrm{~cm})$ filled with field soil in net house. One plant was maintained in each pot. Nitrogen was applied as urea dissolved in water at the rate of $90 \mathrm{~kg} \mathrm{~N}$ ha-1 in the soil 20 days after sowing. Plants without nitrogen served as control. Fully expanded leaf was used for scanning electron microscopy.

Fresh leaf tissue was dehydrated in graded concentration of ethanol (30-100\%). Tissue was dried in liquid $\mathrm{CO}_{2}$ to critical dried point. The tissue was mounted in colloidal silver and coated with a thin film of gold in a sputtering coater. Scanning electron microscope LEO $435 \mathrm{VP}$ was used for observation of the surface of the tissue.

\section{Results and Discussion}

Two types of trichomes were observed on sunflower leaves (Plate 1, Plate2 and 2A); triangular glandular trichomes with three-four tier of cells and globular glandular trichomes with seven tiers of globular cells. Both types of trichomes develop from epidermal cells and exhibit a top cap cell covered with dense wax. Number of globular glandular trichomes and size of both types of trichomes were decreased under nitrogen deficiency.

Differential response of epidermal cells to varying nitrogen supply has been shown in sunflower (Santosh Kumari, 2017). Availability of valine and other branched chain amino acids from the older leaves approaching senescence may regulate the size of trichomes on sunflower leaves under nitrogen deficiency. On one hand, Valine was the most abundant chemical detected in drought sensitive wheat cultivar producing higher number of trichomes (Santosh Kumari and Verma, 2020). On the other hand, benzene derivatives were correlated with low number of trichomes in drought tolerant wheat cultivar. Salicylic acid cross talk with phytohormones (Traw and Bergelson, 2003) like cytokinin may be involved in trichome development under varying levels of nitrogen availability.

Glandular trichomes are associated with plant fitness to the changing environment. The two capitates glandular trichomes are variable in stalk cell number, length and glandular head morphology in sunflower. Trichomes population of different developmental stages occur at the same time in sunflower leaves (Santosh Kumari, 2017) under varying levels of nitrogen supply.

P-Menthanol crystals (Plate1A) on the cuticular surface of leaf indicate the type of secondary chemical composition produced by sunflower plants. Menthanol and cineole biosynthesis starts with the biosynthesis of limonene (terpene). Leucoplasts, cytosol, endoplasmic reticulum and mitochondria are involved in the biosynthesis of limonene and plant volatiles.

Cineol or Eucalyptol is the major constituent of essential oils in plants and the most potent allelochemical and growth inhibitor of many grasses (Muller et al., 1964). The commercial herbicide is 2-Benzyl ether substituted analog of monoterpenes 1, 4- cineol. Glandular trichomes and Azulene (also called guaiene) production in giant trichomes was reduced by herbicides treatments (Stahl and Wollensah, 
1986). Azulene has been associated with giant glandular trichomes (Santosh Kumari and Verma, 2020) under unfavourable growth conditions and $\beta$-Caryophyllene and $\delta$ Cadinene under normal growth conditions in

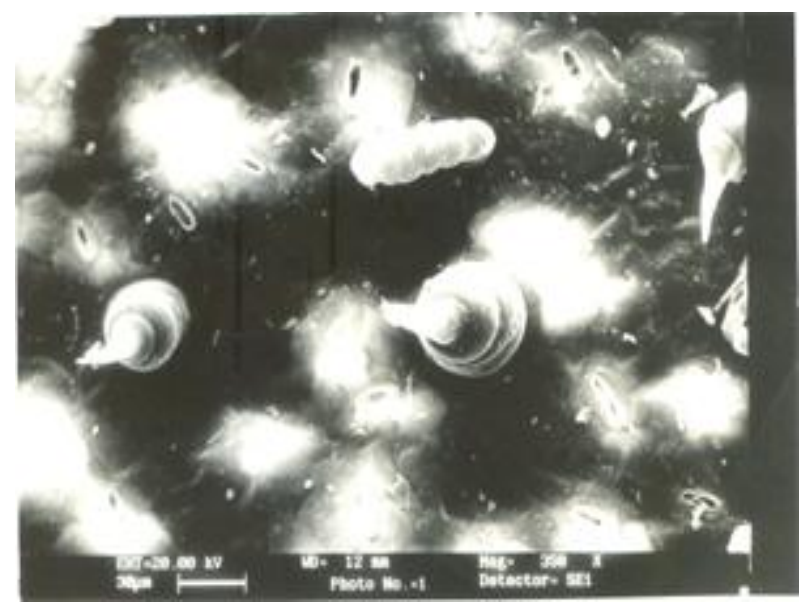

drought tolerant wheat. However, a multiproduct enzyme involved in $\beta-$ Caryophyllene and $\delta$-Cadinene have been reported in glandular trichomes of sunflower (Göpfert et al., 2009).

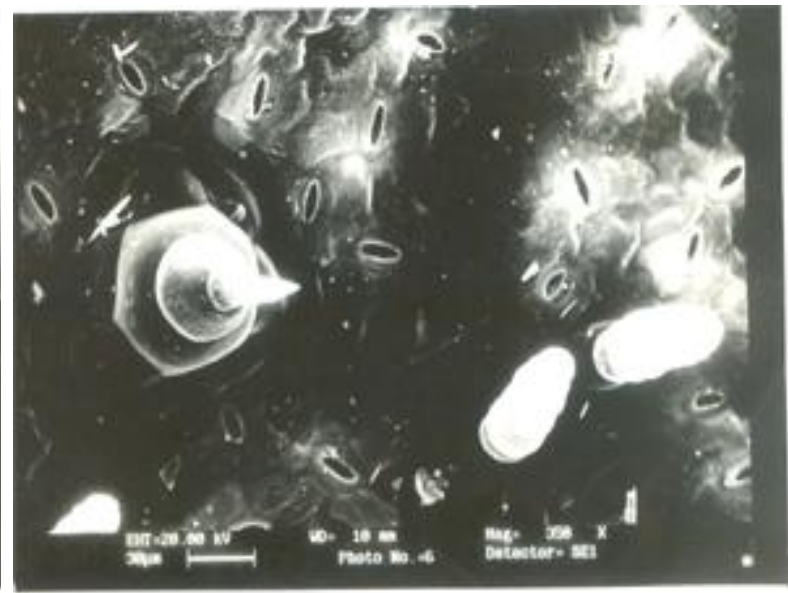

Plate1. Scanning electron micrograph of Trichomes morphology on sunflower leaves under two levels of nitrogen

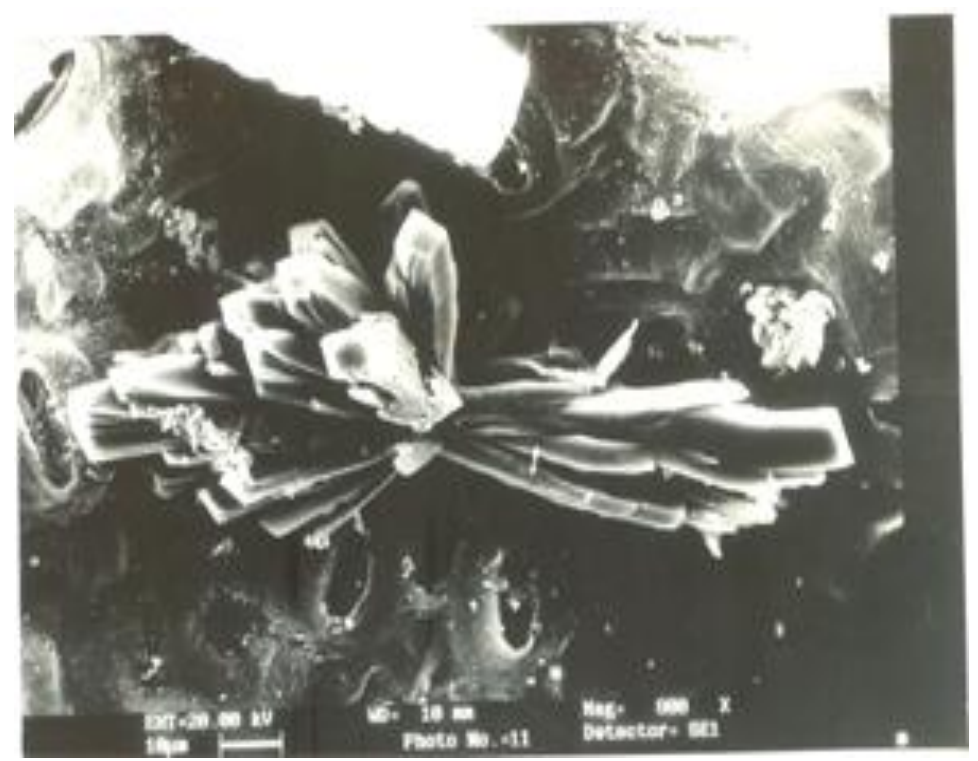

Plate1A.Wax crystals(p-Menthanol) on leaf surface of sunflower 

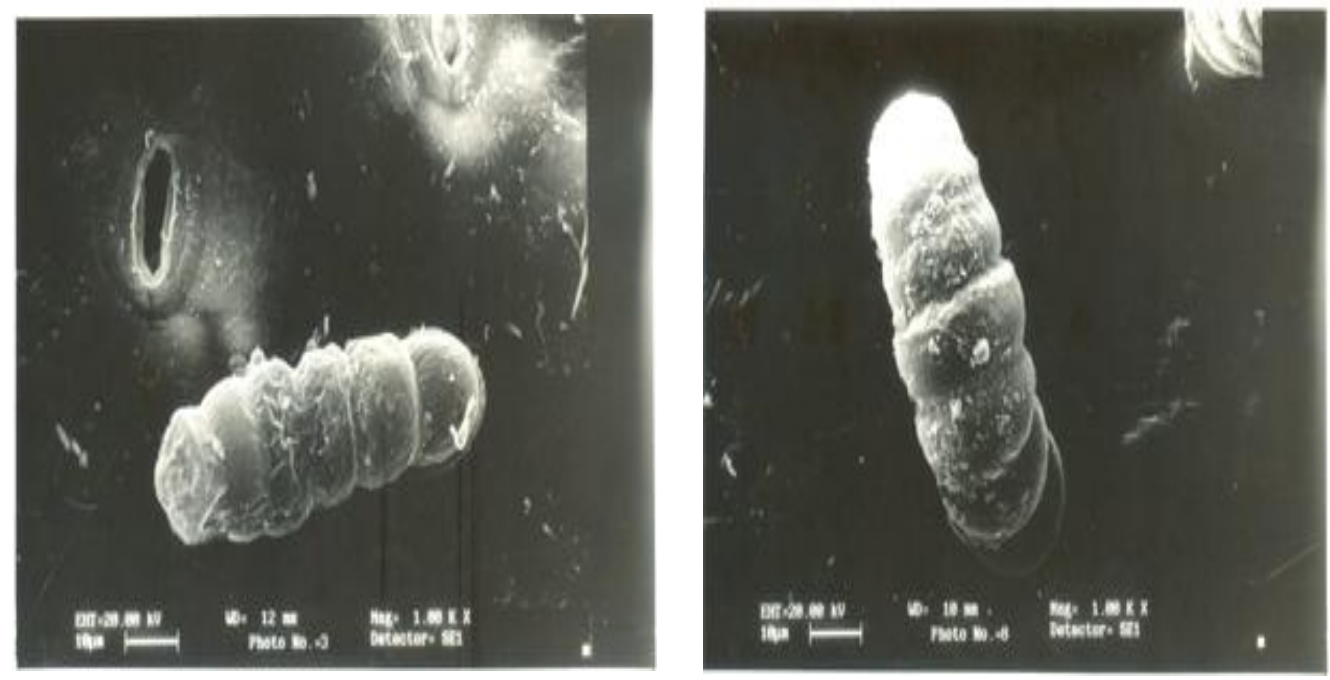

\section{Plate2. Scanning electron micrograph of globular glandular trichomes on sunflower leaves under two levels of nitrogen}
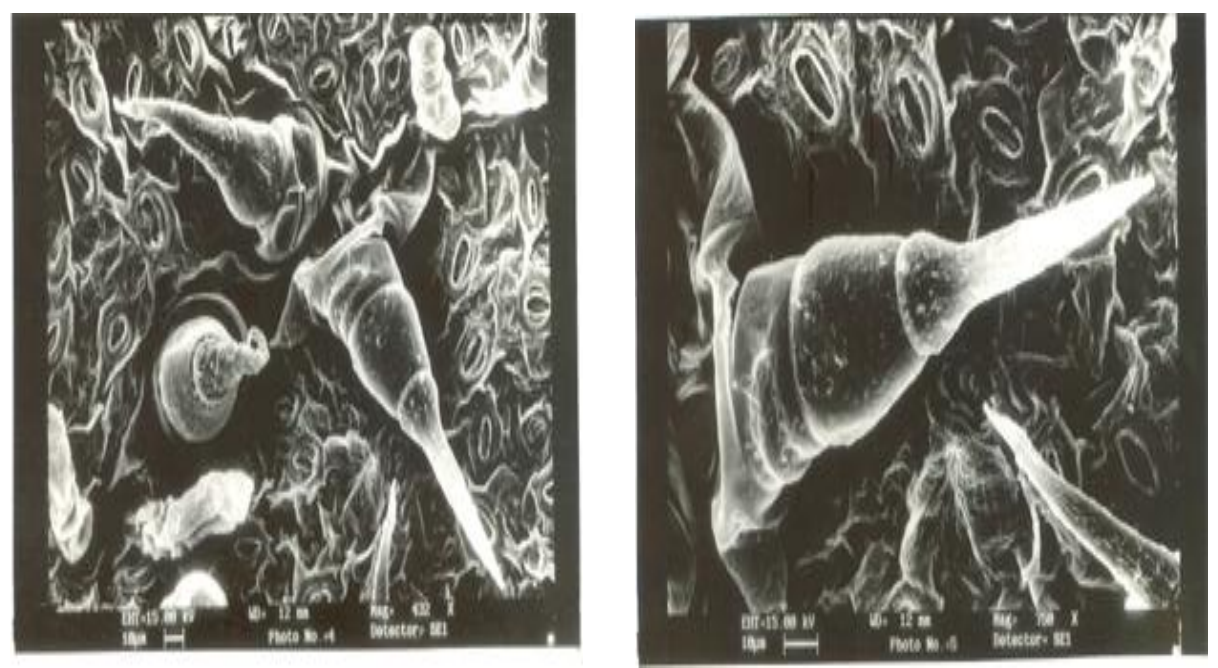

\section{Plate2A. Scanning electron micrograph of triangular glandular trichomes on sunflower leaves under two levels of nitrogen}

Since, changes in the amino acid composition and water regimes are interrelated and constitute one of the adaptive characters of resistance under water deficit conditions (Protsenko et al., 1968). Higher availability of nitrogen increases cytokinin levels, increased leaf area, transpiration and water loss that results in faster senescence of older lower leaves and changes in amino acids composition in sunflower (Santosh Kumari, 1987). Therefore, Trichome development is controlled by external environment and internal plant processes involving carbon and nitrogen metabolism and phytohormones associated with these biosynthetic pathways. 


\section{Acknowledgement}

Scanning electron microscopy (SEM) facility provided by AIIMS, Delhi is thankfully acknowledged.

\section{References}

Muller C. H., Muller W. H. and Haines B. L. (1964) Volatile growth inhibitors produced by aromatic shrubs. Science, 143:471 - 473.

Protsenko, D.F., Shmat'ko, I. G. and Rubanyuk, E. A. (1968) Drought resistance of winter wheats in relation to their amino acid content. Soviet Plant Physiol., 15: 567 - 573.

Santosh Kumari (1987) Effect of growth regulators on growth and metabolism of bajra (Pennisetum typhoides L.) and sunflower (Helianthus annuus L.) under simulated drought conditions. Ph. D. Thesis, COBS\&H, H.A.U., Hisar, Haryana.

Santosh Kumari (2017) Effects of nitrogen levels on anatomy, growth, and chlorophyll content in sunflower (Helianthus annuus L.) leaves. Journal of Agricultural Science, 9(8):208 - 219.
DOI:10.5539/jas.v9n8p208

Santosh Kumari and Verma V. K. (2020) Trichomes and cuticular wax morphology on flag leaves of drought sensitive and drought tolerant wheat (Triticum aestivum L.) under unfavourable growth conditions. International Journal of Current Microbiology and Applied Sciences, 9(2):2740 - 2747.

Stahl, E. and Wollensah, A. (1986) Observations on the Function of the Glandular Hairs of Yarrow 4th Report: Effects of selective herbicides on the glandular hairs and tissue of the florets. Journal of Plant Physiol., 122: 93-96.

Traw, M. B. and Bergelson, J. (2003) Interactive Effects of Jasmonic Acid, Salicylic Acid, and Gibberellin on Induction of Trichomes in Arabidopsis. Plant Physiol, 133:1367-1375.

Göpfert, J.C., MacNevin, G., Ro, D. K. and Spring, O. (2009) Identification, functional characterization and developmental regulation of sesquiterpene synthases from sunflower capitate glandular trichomes. BMC Plant Biology, 9:86.

\section{How to cite this article:}

Santosh Kumari. 2020. Trichomes Size and Structure in Sunflower (Helianthus annuus L.) Leaf under Nitrogen Deficiency. Int.J.Curr.Microbiol.App.Sci. 9(03): 2318-2322. doi: https://doi.org/10.20546/ijcmas.2020.903.263 